\title{
ENTREVISTA COM GUILHERME GONTIJO FLORES
}

\section{INTERVIEW WITH GUILHERME GONTIJO FLORES}

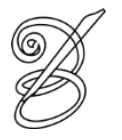

\author{
Entrevistado por: \\ Rodrigo Tadeu GONÇALVES* \\ Layla Gabriel de OLIVEIRA** $^{* *}$ \\ Universidade Federal do Paraná \\ Curitiba, Paraná, Brasil
}

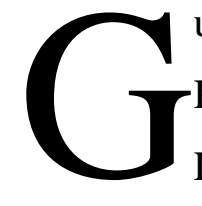

uilherme Gontijo Flores é licenciado em Língua Portuguesa e Literaturas de Língua Portuguesa (2005) pela Universidade Federal do Espírito Santo; mestre em Estudos Literários (2007) pela Universidade Federal de Minas Gerais; doutor em Letras Letras Clássicas (2014) pela Universidade de São Paulo. Realizou pesquisa de pós-doutorado (2018-2019) na Universidade Estadual Paulista Júlio de Mesquita Filho.

Autor dos poemas de brasa enganosa (2013), Tróiades (2014-2015 www.troiades.com.br), l'azur Blasé (2016), Naharia (2017) e carvão $\because$ capim (2018), além do romance História de Joia (2019) e dos ensaios A mulher ventriloquada: o limite da linguagem em Arquíloco (2018) e Algo infiel: corpo performance tradução (2017), escrito em parceria com Rodrigo Tadeu Gonçalves e fotos de Rafael Dabul. Entre seus prêmios constam: Prêmio de Tradução, APCA (Associação Paulista dos Críticos de Arte) em 2013 pela Anatomia da melancolia, de Robert Burton, e em 2017, pelo livro Fragmentos Completos, da poeta grega Safo; Prêmio Paulo Rónai de Tradução, Biblioteca Nacional (2015) pelas Elegias de Sexto Propércio; Prêmio Jabuti de Tradução, Câmara Brasileira do Livro (2014) também pela Anatomia da melancolia.

É coeditor da revista e blogescamandro: poesia tradução crítica (www.escamandro.wordpress.com) e membro fundador do grupo Pecora Loca, dedicado a poesia/performance $\mathrm{e}(\mathrm{m})$ tradução.

RECEBIDO EM: 29 de outubro de 2019

ACEITO EM: 25 de fevereiro de 2020

PUBLICADO EM: março 2020 
1 Você hoje é muito reconhecido nacionalmente pelo seu trabalho com tradução. Quando você começou a traduzir?

Comecei a traduzir ainda na graduação em Letras na Ufes, creio que em 2004. Em 2005 eu passei o ano lendo os poetas romanos para escolher um que pudesse ser meu assunto de monografia e posteriormente mestrado; depois de matutar um bocado, fiquei com Sexto Propércio, que acabou virando verdadeiramente uma paixão. Mas nesse período todo eu sempre traduzi muita poesia esparsa de autores que admiro: traduzo um poema estrangeiro quase sempre que ele me toca; é um modo de responder a esse afeto e incorporá-lo um pouco mais.

\section{O que te motivou? Teve um trabalho especifico?}

Certamente tenho duas motivações que hoje reconheço. A primeira e talvez fundamental é que, como disse, eu traduzo pra me relacionar com as obras e com os autores,

404 fui descobrindo na tradução um caminho de crítica minuciosa, leitura obcecada talvez, que preciso ter com certas obras. A segunda foi o apoio, incentivo, aprendizado que tive com o Raimundo Carvalho, magister maximus na minha formação: com ele eu pude discutir muito inúmeros problemas de poética, língua, tradução; tive ali uma formação que transcende em muito o modelo acadêmico, tanto que hoje ele é pra mim um grande amigo. O trabalho que surgiu ali foi o Propércio, como disse, mas retorno ao Raimundo sempre que hesito, sempre que tento algo, principalmente no mundo antigo.

Você traduz de várias línguas, entre elas inglês, espanhol, alemão, provençal, latim e grego. Tem alguma coisa que mais te surpreendeu ao aprender e traduzir dessas diferentes línguas? A sua relação com o português, por exemplo, permaneceu a mesma? Tem uma coisa que me perturba regularmente: a sintaxe de cada língua tem muitas particularidades, e os grandes autores - sobretudo poetas - costumam ser grandes sintaxistas também; então há um tensionamento absurdo na recriação de um efeito de sintaxe. Por exemplo, Paul Celan quebra seus versos de modo a adiar muito o cerne do que está dizendo, mas faz isso a partir de uma sintaxe razoavelmente comum no alemão; para conseguir um pouco desse "suspense frasal", eu optei por germanizar sutilmente a sintaxe do português. 
O resultado dessas leituras de outras línguas é, com certeza, um estranhamento da própria língua, que perde o caráter de "natural” para assumir seu caráter histórico. Amo essa experiência de retornar à própria língua como se ela agora fosse infamiliar (penso no conceito de Unheimiliche em Freud, mas não só).

3 É comum ouvir, entre aqueles que mexem com tradução, que alguma coisa é intraduzível. O que você pensa disso?

Isso é ilusão criada por uma teoria tradicional de linguagem que hipostasia o sentido. Em outras palavras, perda de tempo. O que existe é o hipertraduzível, e a angústia do tradutor, que só tem uma vida.

4 Qual foi o trabalho tradutório mais desafiador que você já encontrou? Qual foi a solução?

Difícil decidir, porque cada trabalho (cada língua, cada época, cada autor, cada discurso) apresenta problemas muito singulares. Nesse sentido, talvez o mais difícil seja encarar aquilo que ainda não conhecemos. Pode ser por isso que vejo muita dificuldade hoje em Rabelais: é um autor que não aceita um estilo único, mas vai se metamorfoseando de capítulo em capítulo, livro em livro; como tradutor, tento assumir essa metamorfose constante, e assim nunca posso dizer que entendi seu estilo e criei um método de tradução para ele. Estou o tempo inteiro reinventando o método de acordo com o desafio.

Hoje em dia, a discussão acerca da tradução e dos estudos da tradução estão em evidência dentro e fora da academia. As noções do que significa traduzir e a fidelidade do tradutor ao texto original estão sendo revistas e desestabilizadas, de uma forma positiva. $\mathrm{O}$ que você, como tradutor literário, acha sobre essa discussão? Um autor pode ser fiel ao texto? Como você vê os limites entre a adaptação, a tradução e métodos como a transcriação de Haroldo de Campos, por exemplo?

Eu recuso completamente os contratos maritais das metáforas tradutórias, e com eles também a noção de fidelidade (assim, adeus belles infidèles, traduttore traditore etc.) ou de transporte. A tradução literária que me interessa - e a chamo sempre de poética, porque é um fazer, um criar paralelo - pode ser mais feliz no exato momento em que mais se distancia, 
porque tem o dever de criar um texto forte em sua língua, em seu tempo. Nesse aspecto, Haroldo de Campos é o novo patriarca da tradução poética no Brasil, ao lado de Odorico Mendes e Guilherme de Almeida.

5 Além de diversas realizações acadêmicas, o seu currículo mais recente também conta com dois filhos pequenos. Como é ter que trabalhar e conciliar a paternidade? Existe uma rotina que te ajude a manejar as tarefas?

Eu sempre digo que tempo a gente faz, depende mais da nossa paixão do que de uma cronometragem (claro, tirando os impedimentos reais da vida, como proletarização do sujeito, ou horas e horas em descolamento de trabalho, estudo e casa). Ter dois filhos é a percepção de um outro tempo em minha vida, que demanda abertura pra eles, sem ceder minha paixão pela poesia. Então invento horários, ritmos, que variam ao longo do ano, dos semestres, ou mesmo de uma semana; tento ter algum tipo de rotina, como traduzir sempre pela manhã, mas não consigo de fato, então traduzo sempre que surge um tempo, aceito apenas o ócio fértil, e 406 curtir meus filhos é um: cansaço que me renova pra criar.

6 Você e vários outros tradutores ligados à UFPR (Caetano Galindo, Maurício Cardozo, Regina Przybycien, por exemplo), têm colecionado prêmios nacionais por várias de suas traduções. Como você avalia esse reconhecimento? Qual é a relevância desses prêmios?

É fundamental pra fazer o Brasil ter o tamanho que tem. Não é mais aceitável um mundo que não sai do eixo RJ-SP, então comemoro as produções vindas de outros centros (e não só do Paraná) que recebem atenção, porque é assumindo lugares de mídia e premiação que podemos fazer a ampliação do espectro. A relevância do reconhecimento da UFPR é esta: abrir os olhos do leitor, fazer com que mais gente perceba como o mundo fervilha em toda parte. 
7 Como você vê a relação entre a sua atuação como professor universitário, tradutor e formador de tradutores e tradutoras na graduação e pós-graduação?

É o grande eixo que garante os meus projetos: como professor universitário e pesquisador, eu posso propor e realizar projetos de longo prazo que seriam impossíveis no mercado privado, porque não preciso pagar as minhas contas apenas com o que produzo quantitativamente. Sem desmerecer grandes tradutores fora da academia (penso em Denise Bottman pra ficar em apenas um nome), acredito que a fusão entre pesquisa acadêmica e tradução literária tem produzido a maior parte do que há de melhor na tradução brasileira, porque busca obras inesperadas e pode traduzir com um nível de experimento e qualidade que só costuma acontecer quando há um prazo alargado de trabalho.

8 Que conselhos você daria para os jovens que se iniciam na tradução hoje?

Entendam que o principal não é o domínio da língua da qual se traduz, mas sim uma capacidade de escrita na língua em que se traduz. Em outras palavras, um bom tradutor deve ser um virtuose da própria língua.

9 Por último, qual foi o trabalho que você mais gostou de traduzir até agora?

Os poemas rítmicos da Antiguidade (Safo, Horácio, etc.), porque com eles desdobro a tradução em performance vocal, posso cantar com o grupo Pecora Loca, fazer algo acontecer para além do papel, tocar pessoas que nunca abririam um livro de poesia antiga na vida. É um trabalho inacabado, porque não terminei de traduzir tudo que pode entrar no repertório, mas sobretudo porque performar o canto é em si um inacabamento contínuo. Eis o fascínio.

\footnotetext{
* Rodrigo Tadeu GONÇALVES - Bacharel em Letras - Latim (2004) e em Letras - Português e Inglês (2003) pela Universidade Federal do Paraná. Doutor (2008) e Mestre (2004) em Letras pela mesma instituição. Realizou pesquisa pós-doutorado na Université Paris-Sorbonne/ENS/CNRS - Centre Léon Robin, CNRS, França. Professor associado II na Universidade Federal do Paraná. Pesquisador do CNPq nível 2 (2017-2020; 20202023). Diretor da Editora UFPR. Universidade Federal do Paraná, Setor de Ciências Humanas, Departamento de Polonês, Alemão e Letras Clássicas. Curitiba, Paraná, Brasil. Currículo acadêmico: http://lattes.cnpq.br/0497560630462156 ORCID: https://orcid.org/0000-0002-2472-1430

E-mail: goncalvesrt@gmail.com
} 
** Layla Gabriel de OLIVEIRA - Graduanda em Letras - Português pela Universidade Federal do Paraná. Universidade Federal do Paraná, Setor de Ciências Humanas, Departamento de Literatura e Linguística. Curitiba, Paraná, Brasil.

Currículo acadêmico: http://lattes.cnpq.br/1282067103987880

ORCID: https://orcid.org/0000-0002-3142-6739

E-mail: laylaoliveira.ufpr@gmail.com 